\title{
Gold: An Uncommonly Good Catalyst
}

\section{PAPERS AT THE SIXTH INTERNATIONAL CONGRESS}

\author{
Paul A. Sermon \\ Brunel University, Uxbridge, Middlesex, England
}

As long ago as 1834 Michael Faraday reported that gold, like platinum and palladium, but unlike copper and silver, effectively catalysed the reaction between hydrogen and oxygen at ambient temperature (1). However, the more recent and quantitative studies have shown that the adsorptive and catalytic properties of gold with respect to hydrogenation reactions are meagre in comparison with those of the Group VIII metals unless it is supplied with hydrogen atoms or protons from an external source (2). This has been attributed to its lack of vacant $d$-orbitals below about $473 \mathrm{~K}$, a temperature at which $5 d$ electrons may be elevated to the $6 s$ state (2).

Within the last three years a number of reports have appeared in the literature indicating that gold, both in the supported state and in the form of thin films, may be active in dissociatively chemisorbing $\mathbf{H}_{2}$ (3), initiating hydrogen spillover (3), catalysing the hydrogenation of unsaturated molecules (3), catalysing the $\mathrm{H}_{2}-\mathrm{D}_{2}$ exchange (3), catalysing the $\mathrm{H}_{2} / \mathrm{D}_{2}$ exchange between $\mathrm{CH}_{3} \mathrm{SiH}_{3}$ and $\mathrm{CH}_{3} \mathrm{SiD}_{3}(4)$, and catalysing hydrocracking reactions (5). However, this activity was generally lower than that shown by Group VIII metals, although it was unusual and noteworthy in certain respects (3). Defects (6), monatomic or small particles (3), and gold in positive oxidation states (7) might be associated with the sites active in these reactions.

At the Sixth International Congress on Catalysis, held in London in July, two papers were presented relating to the catalytic activity of gold in hydrogen exchange (8) and in hydrocracking (9) reactions. These are unusual since both reported that the activity of gold was higher than that of some other transition metals, including platinum, nickel, rhodium, molybdenum and tungsten.

D. T. Bradshaw, R. B. Moyes and $P$. B. Wells of the University of Hull reported (8) on the littlestudied reactions of silanes over catalysts; in particular the adsorption of and the exchange reactions of methylsilanes $\left(\mathrm{CH}_{3} \mathrm{SiH}_{3}\right.$ and $\mathrm{CH}_{8} \mathrm{SiD}_{3}$ ) over thin films of gold and molybdenum (and other transition metals) between 195 and $273 \mathrm{~K}$. Figure 1 illustrates the reactions involved. These were studied in ultra-high vacuum volumetric apparatus with analysis being carried out by mass spectrometry. The authors were interested in the effects of replacing a carbon atom in $\mathrm{C}_{8} \mathrm{H}_{6}$ with a silicon atom, which, because of its vacant $d$-orbitals allowing back donation of metal $d$-electrons, might be more strongly adsorbed on the metal surface. A consideration of the products of the exchange reactions in Figure 1 shows that only the silyl group undergoes exchange and the inference is that only the silicon atom of the methylsilane is bonded to the metal surface. Methylsilane was found to chemisorb dissociatively on both gold and molybdenum films between 195 and $273 \mathrm{~K}$. The predominant products were hydrogen and methane, in the approximate ratio $20: 1$, and the mechanism of this dissociation/

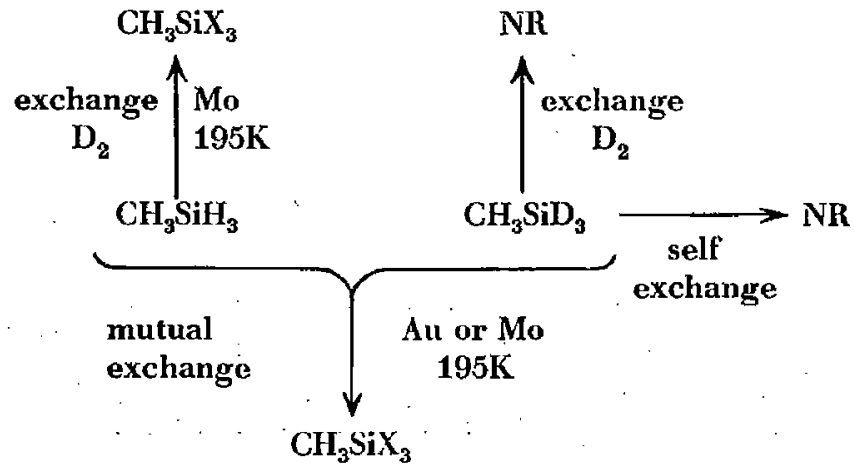

Fig. 1 Exchange reactions studied hy Bradshaw, Moyes and Wells (where $\mathbf{X}=\mathbf{H}$ or $\mathbf{D}$ and $\mathrm{NR}$ denoteis no reaction)

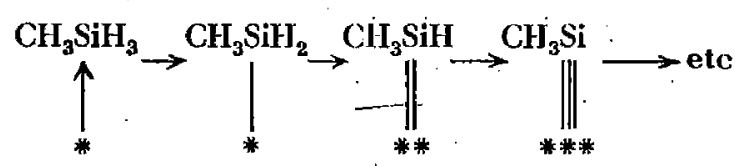

Fig. 2 Decomposition of methylsilane on gold and molybdenum (where * denotes a surface site) 
decomposition is one of dehydrogenation, as shown in Figure 2.

The average composition of the residue which remains multiply bonded to the catalyst surface was $\mathrm{CSiH}_{3-4}$. Of the products of dissociative chemisorption, $\mathrm{CH}_{3} \mathrm{SiH}$ was thought to cause some deactivation of the catalysts, especially since its coverage is almost invariant with pressure. Unfortunately, no results were available on the surface areas of the gold and molybdenum films, but apparent turnover numbers for the exchange reactions at $195 \mathrm{~K}$ (calculated from methylsilane adsorption, assuming that its coverage was the same on gold and molybdenum) were at least five times greater for gold than for molybdenum (or nickel, rhodium or tungsten).

\section{Hydrocracking of Polyethylene}

M. Legate and P. A. Sermon of Brunel University reported on the ability of gold and platinum to catalyse the hydrocracking of polyethylene, a material chosen as a model non-polar polymer (9). These authors started from the premise that if gold and platinum both dissociatively chemisorb hydrogen, both might initiate the spillover of hydrogen to the solid polymer surface where hydrocracking is facilitated. Then the lower adsorptive capacity of gold might prevent it being poisoned by the products of hydrocracking and allow it to act as a more effective hydrocracking catalyst than traditional metals. The polyethylene, in the form of porous sheets, was immersed in $0.3 \mathrm{M}$ solutions of $\mathrm{HAuCl}_{4}$ or $\mathrm{H}_{2} \mathrm{PtCl}_{6}$ at ambient temperature. The hydrophobicity of the polymer slowly diminished and after 24 hours the polymer, which then retained the colour of the acid solutions, was removed, washed, dried in vacuo at $290 \mathrm{~K}$, and then heated in air at $373 \mathrm{~K}$. Within five minutes at $373 \mathrm{~K}$, the original colour (yellow: $\mathrm{HAuCl}_{4}$; orange: $\mathrm{H}_{2} \mathrm{PtCl}_{6}$ ) had turned to mauve (Au/polyethylene) or brown ( $\mathrm{Pt} /$ polyethylene). Polyethylene is susceptible to anionic attack by mineral acids of similar strength and the authors assume that $\mathrm{AuCl}_{4}^{-}$and $\mathrm{PtCl}_{6}^{-}$are retained at the polymer surface and then decompose at $373 \mathrm{~K}$ to give the supported metal crystallites. However, the rate of their decomposition is much faster than previously reported (3), and the exact nature of the adsorbed species and the mechanism of decomposition will be the subject of further study. Electron microscopy indicated that the average size of the particles of gold and platinum was approximately the same ( 35 to $40 \mathrm{~nm})$. The samples contained almost identical concentrations of the metals ( 2.0 weight per cent gold; 2.5 weight per cent platinum). Because of the low adsorptive capacity of gold towards $\mathrm{H}_{2}, \mathrm{CO}$ and $\mathrm{O}_{2}$ it was not possible to compare the surface areas of the two supported metals.

The rates of hydrocracking and the nature of the products were studied in a catalytic flow system using hydrogen, with the sample being heated from ambient temperature to $770 \mathrm{~K}$ at a rate of $10 \mathrm{~K} / \mathrm{min}$ or being held under isothermal conditions. While hydrocracking of the blank polymer was not noted below $500 \mathrm{~K}$ in samples containing either gold or platinum reaction was initiated at $300 \mathrm{~K}$. In all cases at temperatures below $600 \mathrm{~K}$ the products included $\mathrm{CH}_{4}$, $\mathrm{C}_{2} \mathrm{H}_{4}$ and $\mathrm{C}_{2} \mathrm{H}_{6}$. The samples in the order in which they produced these hydrocarbons to the greatest extent were:

\section{$\mathrm{CH}_{4}, \mathrm{C}_{2} \mathrm{H}_{6}: \mathrm{Pt} /$ polyethylene $>\mathrm{Au} /$ Polyethylene $>$ polyethylene}

\section{$\mathrm{C}_{2} \mathrm{H}_{4}$ : polyethylene $>\mathrm{Au} /$ polyethylene $>$ $\mathrm{Pt} /$ polyethylene}

However, gold was the more active at initiating hydrocracking to all products $\left(\mathrm{C}_{1}-\mathrm{C}_{35}\right.$ hydrocarbons). Both metals produced predominantly alkanes, unlike the non-catalysed reaction.

At about $670 \mathrm{~K}$ the polymer melted and at higher temperatures a very different régime existed, with the particles of gold and platinum in the form of a colloidal sol within the liquid polymer. The hydro-

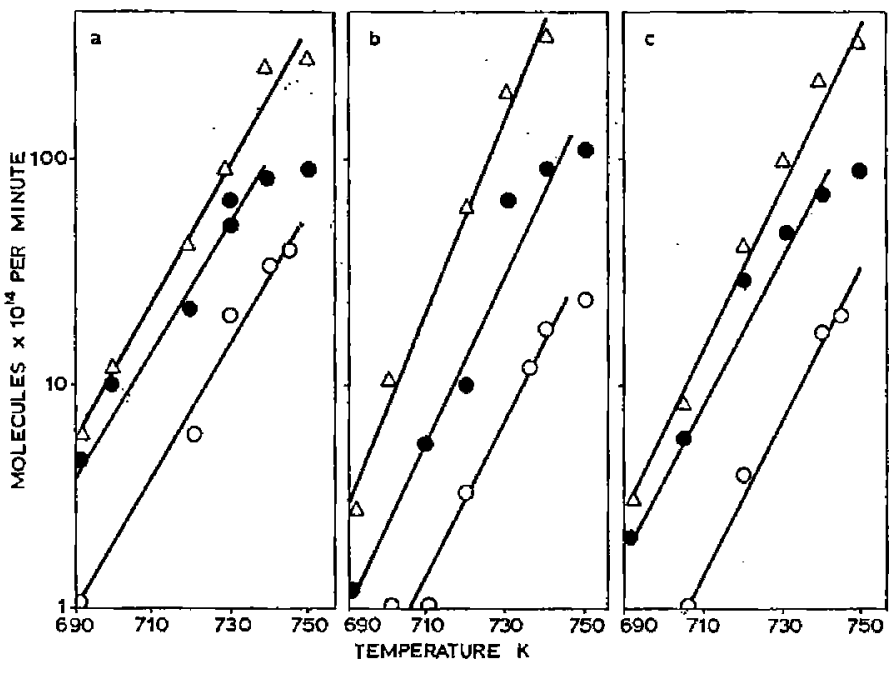

Fig. 3 Rates of hydroeracking of polyethylene in samples of blank polyethylene (O), 2.03 per cent $A u /$ polyethylene $(\Delta)$ and 2.55 per cent Pt/polyethylene (O) at temperatures between 690 and $750 \mathrm{~K}$ to give $\mathrm{C}_{2} \mathrm{H}_{6}$ (Fig. 3a), $\mathrm{C}_{2} \mathrm{H}_{4}$ (Fig. 3h) and $\mathrm{CH}_{4}$ (Fig. 3c) 
cracking of the liquid polymer was then studied in the temperature range 670 to $750 \mathrm{~K}$. At the latter temperature the rate of hydrocracking was at least $10^{5}$ times greater than at $500 \mathrm{~K}$. The products of hydrocracking once again included $\mathrm{CH}_{4}, \mathrm{C}_{2} \mathrm{H}_{4}$ and $\mathrm{C}_{2} \mathrm{H}_{6}$, but now for each of these gold was the most effective catalyst. Its total activity was more than twice that of platinum, which as Figure 3 shows was still a reasonably effective catalyst itself. After cooling, the polymer heated under these conditions was found to consist of rosettes at the centre of which was either a particle of gold or platinum.

Thus gold because of its lower adsorptive capacity became the more effective hydrocracking catalyst.

\section{Conclusion}

However, these and other results may be open to criticism since it has not been possible to determine the surface area of gold and hence to compare the turnover numbers for gold and other metals in these reactions.

Approximately three years ago we were surprised to find even meagre activity for gold in hydrogenation and related reactions; now we must be encouraged further to note that in certain reactions and conditions gold shows activity which is significantly greater than that shown by the transition metals which are generally accepted as the more traditional catalysts.
We may not share all the optimism of the Greek poet and playwright Diphilus expressed in "nothing is more powerful than gold" $(10)$, but we are hopeful of achieving further interesting and useful advances in our knowledge of the catalytic properties of gold.

\section{References}

1 M. Faraday, "Experimental Researches in Electricity", J. M. Dent, London, 1914, p. 94

2 See references $1-8$ given by G. C. Bond and P. A. Sermon, Gold Bull., 1973, 6, (4), 102; Z. Karpiniski and J. K. A. Clarke, 7. Chem. Soc, Faraday Trans. I, $1975,71,(12), 2310 ;$ D. I. Hagen and G. A. Somorjai, F. Catalysis, 1976, 41, (3), 466

3 G. C. Bond, P. A. Sermon, G. Webb, D. A. Buchanan and P. B. Wells, f. Chem. Soc., Chem. Commun., 1973, (13), 444; G. C. Bond and P. A. Sermon, Gold Bull., $1973,6,(4), 102 ;$ D. A. Buchanan and G. Webb, $\mathscr{f}$. Chem. Soc., Faraday Trans. I, 1975, 71, 144; P. A. Sermon and G. C. Bond, to be published

4 D. I. Bradshaw, R. B: Moyes and P. B. Wells, F. Chem. Soc., Chem. Commun., 1975, (5), 137

5 J. M. Penninger, Gold Bull., 1975, 8, (3), 88

6 S. Kishimoto and M. Nishioka, J. Phys. Chem., 1972 76, (13), 1907

7 I. W. Bassi, F. W. Lytle and G. Parravano, 7. Catalysis, $1976,42,(1), 139$

8 D. I. Bradshaw, R. B. Moyes and P. B. Wells, Paper presented at the Sixth International Congress on Catalysis, London, July 1976

9 M. Legate and P. A. Sermon, Paper presented at the Sixth International Congress on Catalysis, London, July 1976

10 G. Agricola, "De Re Metallica", translated by H. C. Hoover and L. H. Hoover, Dover Publ. Inc., New York, 1950 , p. 10

\section{A Rhenium-Gold Contact Alloy for Sensitive Relays}

In a search for a contact material for extremely sensitive relays and electrical measuring instruments, Russian workers have settled on an alloy of gold containing 3 per cent rhenium. The alloy formerly used in this type of relay was a gold alloy with 30 per cent palladium and 10 per cent platinum, this being in the form of $0.15 \mathrm{~mm}$ diameter wire moving between two freely suspended fixed contacts of the same material and also in the form of fine wire. Contact is thus made between two intersecting cylindrical surfaces, but in the cases in question the contact pressure was minute, varying from only 0.0001 to $0.001 \mathrm{gram}$. In these very difficult conditions even normal atmospheric humidity or contamination can adversely affect contact performance.

Gold was considered to be the only possible basis metal for a suitable contact alloy, but increased mechanical strength was desirable as well as complete resistance to organic vapours or other types of pollution. A series of alloying elements including titanium, cobalt, indium and zinc was investigated, but additions of rhenium proved to give optimum results.

This work, reported in a paper by A. $M$. Chernyavskaya, E. P. Razguiyaev and S. A. Telezhkin presented at a conference on rhenium held in Moscow some time ago but only recently published (Issled. Primen. Splavov Reniya, Dokl. Vses. Soveshch. Probl. Reniya, 1975, 182-185) included the determination of resistivities, contact resistances, mechanical properties and thermoelectric effect against copper of alloys with $1,2,3$ and 4 per cent rhenium.

The resistivities naturally increased by comparison with pure gold, but were much lower than with the gold-palladium-platinum alloy, while the thermal e.m.f. against copper was also very much lower.

All four alloys were found to have considerably lower and more stable contact resistances and to be appreciably less liable to sticking over a range of currents up to 200 milliamp, but the 3 per cent alloy gave the best values, with a contact resistance lower by a factor of 5 to 10 compared with the gold-palladiumplatinum alloy, as well as a much greater resistance to deformation.

After these initial tests a number of relays fitted with contacts in 3 per cent rhenium-gold were submitted to extensive industrial resting and found to give a distinct improvement by comparison with those having the older gold-palladium-platinum alloy contacts.

S.H. 